Copyright $\odot 2012$ IEEE. Personal use of this material is permitted. Permission from IEEE must be obtained for all other uses, in any current or future media, including reprinting/republishing this material for advertising or promotional purposes, creating new collective works, for resale or redistribution to servers or lists, or reuse of any copyrighted component of this work in other works. 


\title{
Standardization of DGA Interpretation Techniques using Fuzzy Logic Approach
}

\author{
S. Hmood, A. Abu-Siada, Mohammad A.S. Masoum and Syed M. Islam \\ Electrical and Computer Engineering Department, Curtin University, WA
}

\begin{abstract}
Dissolved gas analysis (DGA) of transformer oil is one of the most effective power transformer condition monitoring tools. There are many interpretation techniques for DGA results. However, all of these techniques rely on personnel experience more than standard mathematical formulation. As a result, various DGA interpretation techniques do not necessarily lead to the same conclusion for the same oil sample. DGA interpretation is yet a challenge in the power transformer condition monitoring research area. To alleviate this issue, this paper introduces a fuzzy logic approach to help in standardizing DGA results quantification and classification using various interpretation techniques such as key gas, Rogers ratio, IEC ratio, Doernenburg and Duval triangle methods. In this context, DGA results for 2000 oil samples have been collected from different transformers of different ratings, life span and operating conditions. Traditional DGA interpretation techniques are used to analyze the results which are then compared with the results of the fuzzy logic models. Results show that the fuzzy logic models enhance the consistency among all current interpretation techniques and can eliminate the need for expert personal to interpret DGA results.
\end{abstract}

Index Terms-- Transformer Diagnosis, Condition monitoring, DGA, Fuzzy Logic.

\section{INTRODUCTION}

$\mathrm{P}$ OWER transformers are vital links in any transmission and distribution network. Monitoring and diagnostic techniques are essential to decrease maintenance and to improve reliability of the equipment. Currently there are several chemical and electrical diagnostic techniques applied for power transformers [1]. The electrical windings in a power transformer consist of paper insulation immersed in insulating oil, hence transformer oil and paper insulation are essential sources to detect incipient faults, fast developing faults, insulation trending and generally reflects the health condition of the transformer. During faults and due to electrical and thermal stresses that in-service transformer exhibits, oil and paper decomposition occurs evolving gases that will decrease the heat dissipation capability and the dielectric strength of the oil [2]. Gases produced due to oil decompositions are hydrogen $\left(\mathrm{H}_{2}\right)$, methane $\left(\mathrm{CH}_{4}\right)$, acetylene $\left(\mathrm{C}_{2} \mathrm{H}_{2}\right)$, ethylene $\left(\mathrm{C}_{2} \mathrm{H}_{4}\right)$ and ethane $\left(\mathrm{C}_{2} \mathrm{H}_{6}\right)$. On the other hand paper decomposition produces carbon monoxide (CO) and carbon dioxide $\left(\mathrm{CO}_{2}\right)$ [2]. Transformer oil dissolved gas analysis (DGA) is widely used to detect incipient faults and it can be used to determine the transformer failure rank [3]. There are

All authors are with the Department of Electrical Engineering, Curtin University, Perth, WA6102, Australia (e-mail: a.abusiada@curtin.edu.au). many DGA interpretation techniques such as key gas method [4], Doernenburg, IEC and Rogers ratio methods [5, 6] and Duval triangle method [7] have been reported in the literatures. However, all of these methods rely on personnel experience more than mathematical formulation and they do not necessarily lead to the same conclusion for the same oil sample. Precise DGA interpretation is yet a challenge in the power transformer condition monitoring research area. Availability of DGA data history has recently motivated researchers to develop a standard technique for DGA interpretation based on mathematical techniques [8-13]. Transformer internal faults are divided into thermal and electrical categories. Each fault category evolves particular characteristic gases. However, the analysis is not always straight forward as there may be more than one fault present at the same time. From the type and amount of gas, the fault nature can be determined. Various faults produce energy from low level to very high level sustained arcing. The low level energy is a partial discharge, which produces $\mathrm{H}_{2}$ and $\mathrm{CH}_{4}$. The arcing is capable of generating all gases including $\mathrm{C}_{2} \mathrm{H}_{2}$ [2]. Except for $\mathrm{CO}$ and $\mathrm{CO}_{2}$, all other gases are formed due to the decomposition of oil. $\mathrm{CO}$ and $\mathrm{CO}_{2}$ in DGA represent a good source for paper monitoring. Presence of $\mathrm{C}_{2} \mathrm{H}_{2}$ in the oil is an indication of high energy arcing.

\section{FUZZY LOGIC MODELS}

In this section, fuzzy logic models are developed to aid in standardizing the results of various DGA interpretation techniques. Each fuzzy logic model is developed in accordance to fuzzy inference flow chart shown in Fig. 1. Input variables to the model are the 7-key gases in particle per million (ppm). The output of the each model is divided into 6 sets covering all fault conditions that a transformer may exihibit in addition to a normal condition (F5) and out of code (F6) for ratio methods as summarised in table I. The ouput membership functions for all models is shown in Fig. 2

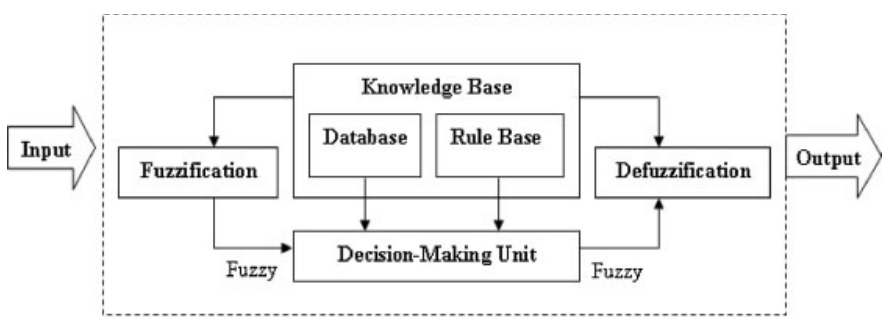

Fig. 1. Fuzzy logic model flow chart 
Each model is built using the graphical user interface tools provided by MATLAB. Each input was fuzzified into various sets (normal to significant) of triangular combination membership functions (MF).

TABLE I

FUZZY LOGIC OUTPUT SETS

\begin{tabular}{|c|c|c|c|c|c|}
\hline & \multicolumn{3}{|c|}{ Faults } & \multirow[b]{2}{*}{ F6 } & \multirow[b]{2}{*}{ F5 } \\
\hline 疍 & F1 \& F2 & F3 & F4 & & \\
\hline 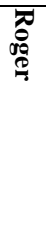 & $\begin{array}{l}\text { Thermal Fault } \\
<150^{\circ} \mathrm{C} \\
\text { Thermal Fault } \\
\text { between } 150-300^{\circ} \mathrm{C} \\
\text { Thermal Fault } \\
\text { between } 300-700^{\circ} \mathrm{C} \\
\text { Thermal Fault } \\
>700^{\circ} \mathrm{C}\end{array}$ & $\begin{array}{l}\text { Partial Discharge } \\
\text { (PD) of low energy } \\
\text { Partial Discharge of } \\
\text { High energy } \\
\text { Continues Sparking } \\
\text { Discharge of high } \\
\text { energy }\end{array}$ & $\begin{array}{l}\text { PD with } \\
\text { tracking }\end{array}$ & $\begin{array}{l}0 \\
\vdots \\
0 \\
0 \\
0 \\
0 \\
0\end{array}$ & 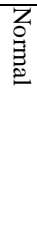 \\
\hline 青 & $\begin{array}{l}\text { Thermal Fault } \\
<150^{\circ} \mathrm{C} \text {. } \\
\text { Thermal Fault } \\
\text { between } 150-300^{\circ} \mathrm{C} \text {. } \\
\text { Thermal Fault } \\
\text { between } 300-700^{\circ} \mathrm{C} \\
\text { Thermal Fault } \\
>700^{\circ} \mathrm{C}\end{array}$ & $\begin{array}{l}\text { Partial Discharge of } \\
\text { low energy } \\
\text { Partial Discharge of } \\
\text { High energy } \\
\text { Continues Sparking } \\
\text { Discharge of high } \\
\text { energy }\end{array}$ & $\begin{array}{l}\text { PD of } \\
\text { low } \\
\text { energy } \\
\text { density } \\
\text { PD of } \\
\text { high } \\
\text { energy } \\
\text { density }\end{array}$ & $\begin{array}{l}0 \\
\stackrel{0}{0} \\
0 \\
0 \\
0 \\
0 \\
0\end{array}$ & $\begin{array}{l}2 \\
0 \\
0 \\
\vdots \\
\end{array}$ \\
\hline 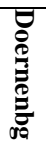 & $\begin{array}{l}\text { Thermal } \\
\text { Decomposition }\end{array}$ & Arcing/Corona & Corona & $\begin{array}{l}0 \\
\vdots \\
0 \\
0 \\
0 \\
0 \\
0\end{array}$ & $\begin{array}{l}\text { Z } \\
\text { Z } \\
\text { 蒠 } \\
0\end{array}$ \\
\hline 导 & $\begin{array}{l}\text { Hot spot } \\
\text { Hot spot }<200^{\circ} \mathrm{C} \\
\text { Hot spot between } \\
200-700^{\circ} \mathrm{C} \\
\text { Hot spot }>400^{\circ} \mathrm{C}\end{array}$ & $\begin{array}{l}\text { Corona discharge } \\
\text { High Energy Arcing } \\
\text { Low Energy Arcing }\end{array}$ & $\begin{array}{l}\text { PD } \\
\text { Mixed } \\
\text { Thermal } \\
\& \\
\text { Electrical } \\
\text { faults }\end{array}$ & $\begin{array}{l}0 \\
\vdots \\
0 \\
0 \\
0 \\
\vdots \\
0\end{array}$ & $\begin{array}{l}\mathrm{Z} \\
\mathrm{O} \\
\mathrm{g} \\
\mathrm{g} \\
\mathrm{g}\end{array}$ \\
\hline 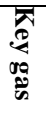 & $\begin{array}{l}\text { Over heated oil } \\
\text { Over heated } \\
\text { cellulosic }\end{array}$ & $\begin{array}{l}\text { Arcing in oil } \\
\text { Corona in oil }\end{array}$ & PDs & $\begin{array}{l}0 \\
\vdots \\
0 \\
0 \\
0 \\
0 \\
\stackrel{0}{D}\end{array}$ & $\begin{array}{l}2 \\
0 \\
0 \\
3 \\
0\end{array}$ \\
\hline
\end{tabular}

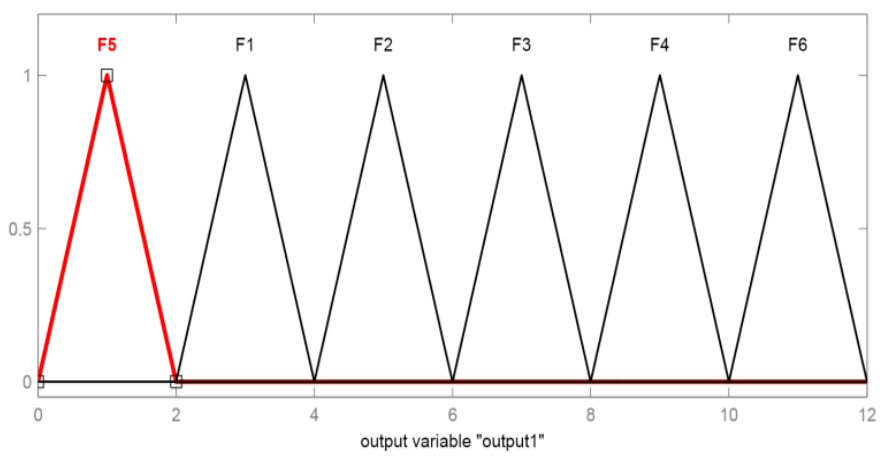

Fig.2 Fuzzy logic models output membership functions

Centre-of-gravity which is widely used in fuzzy models, was used for defuzzification method where the desired output $z_{0}$ is calculated as [14] :

$$
z_{0}=\frac{\int z \cdot \mu_{c}(z) d z}{\int \mu_{c}(z) d z}
$$

where $\mu_{c}(\mathrm{z})$ is the membership function of the output.
A set of fuzzy logic rules in the form of (IF-AND-THEN) statements relating the input to the output variables was developed based on transformer's diagnostic and test data interpretation techniques as is elaborated in the following section.

\section{FUZZY LOGIC MODELS FOR VARIOUS DGA METHODS}

\section{A. Key Gas Method}

Membership functions for input variables are established based on the amount of gases present in oil. Set of fuzzy rules relates the input variables to the output variables are developed based on transformer's diagnostic and test data interpretation techniques as shown in Fig. 3. The model is tested with inputs, $\mathrm{H}_{2}$ (75 ppm), $\mathrm{CH}_{4}$ (75 ppm), $\mathrm{C}_{2} \mathrm{H}_{6}(50$ ppm), $\mathrm{C}_{2} \mathrm{H}_{4}$ (50 ppm), $\mathrm{C}_{2} \mathrm{H}_{2}$ (50 ppm), $\mathrm{CO}$ (200 ppm) and $\mathrm{CO}_{2}$ $(1500 \mathrm{ppm})$ as detected in one of the transformer oil samples results using DGA. The model output is 5 as shown in Fig. 3. This is corresponding to F2 (thermal) fault as can be seen from Table I and Fig. 2. This is attributed to the high level of $\mathrm{C}_{2} \mathrm{H}_{2}$ and the critical level of $\mathrm{C}_{2} \mathrm{H}_{4}$.

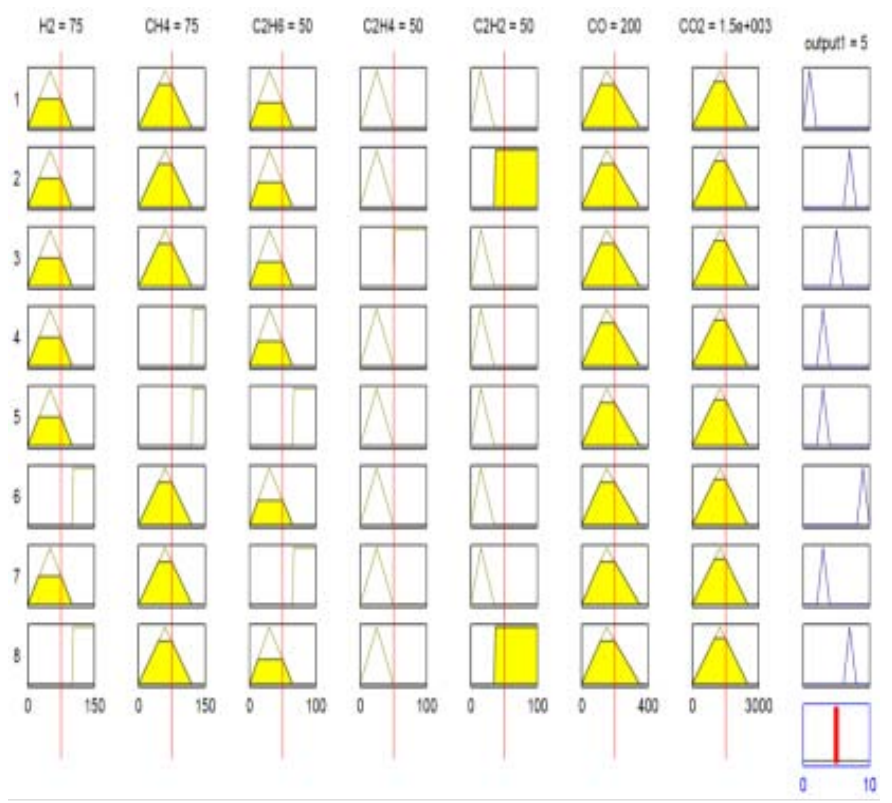

Fig. 3. Key gas Fuzzy rules

\section{B. Doernenburg Method}

Set of fuzzy rules relates the input and the output variables are developed for this method as shown in Fig. 4. The model is tested with inputs, $\mathrm{CH}_{4} / \mathrm{H}_{2}(1), \mathrm{C}_{2} \mathrm{H}_{2} / \mathrm{C}_{2} \mathrm{H}_{4}(0.1), \mathrm{C}_{2} \mathrm{H}_{6} / \mathrm{C}_{2} \mathrm{H}_{2}$ (0.5), $\mathrm{C}_{2} \mathrm{H}_{2} / \mathrm{CH}_{4}$ (1) as detected in one of the transformer oil samples DGA results. Fuzzy logic model output is 1 , which is corresponding to F5 (normal condition).

\section{Duval Triangle fuzzy logic}

Set of fuzzy rules relates the input to the output variables is developed for this method as shown in Fig. 5. The model is tested with inputs, $\mathrm{CH}_{4} /\left(\mathrm{C}_{2} \mathrm{H}_{2}+\mathrm{C}_{2} \mathrm{H}_{4}+\mathrm{CH}_{4}\right) \quad$ (43.3\%), $\mathrm{C}_{2} \mathrm{H}_{4} /\left(\mathrm{C}_{2} \mathrm{H}_{2}+\mathrm{C}_{2} \mathrm{H}_{4}+\mathrm{CH}_{4}(80.1 \%)\right.$ and $\mathrm{C}_{2} \mathrm{H}_{2} /\left(\mathrm{C}_{2} \mathrm{H}_{2}+\mathrm{C}_{2} \mathrm{H}_{4}+\mathrm{CH}_{4}\right)$ $(50 \%)$ as detected in one of transformer oil samples results using DGA. The fuzzy logic output is 5.04 which is corresponding to F5 (normal condition). 


\section{IEC Ratio Method:}

The developed set of fuzzy rules relates the input and the output variables is shown in Fig. 6. The model is tested with inputs, $\mathrm{C}_{2} \mathrm{H}_{2} / \mathrm{C}_{2} \mathrm{H}_{4}$ (2.5), $\mathrm{CH}_{4} / \mathrm{H}_{2}$ (2.5) and $\mathrm{C}_{2} \mathrm{H}_{4} / \mathrm{C}_{2} \mathrm{H}_{6}$ (2.5) as detected in one of transformer oil samples results using DGA. The fuzzy logic model output is 7.07 , which is corresponding to F3 (partial discharge).

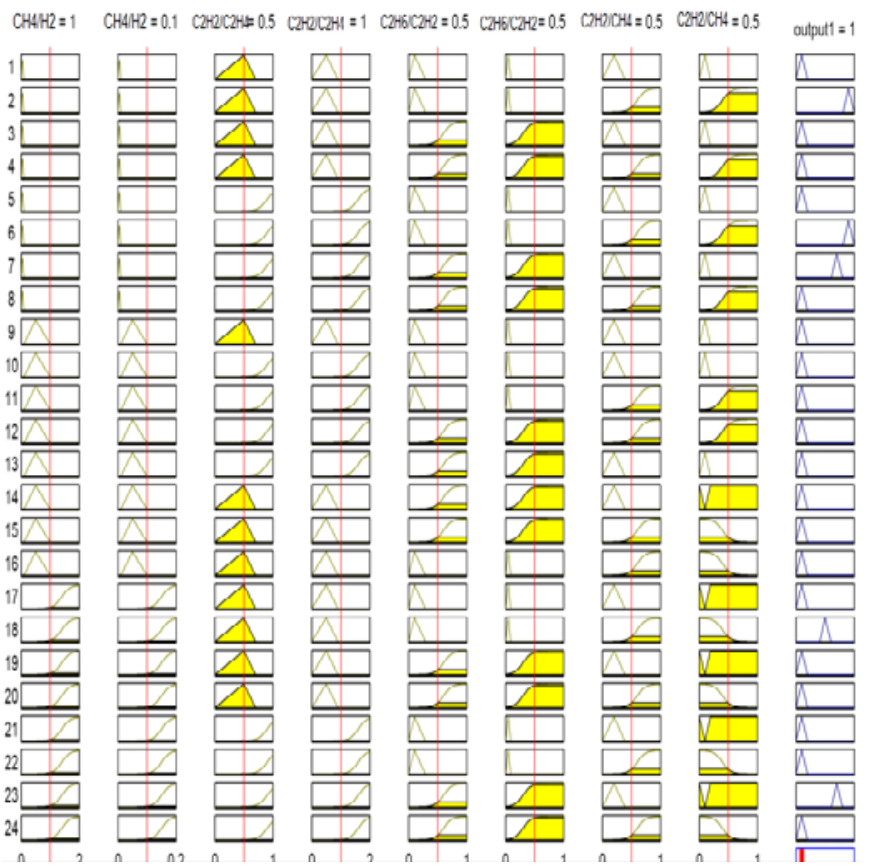

Fig. 4. Doernenburg fuzzy rules
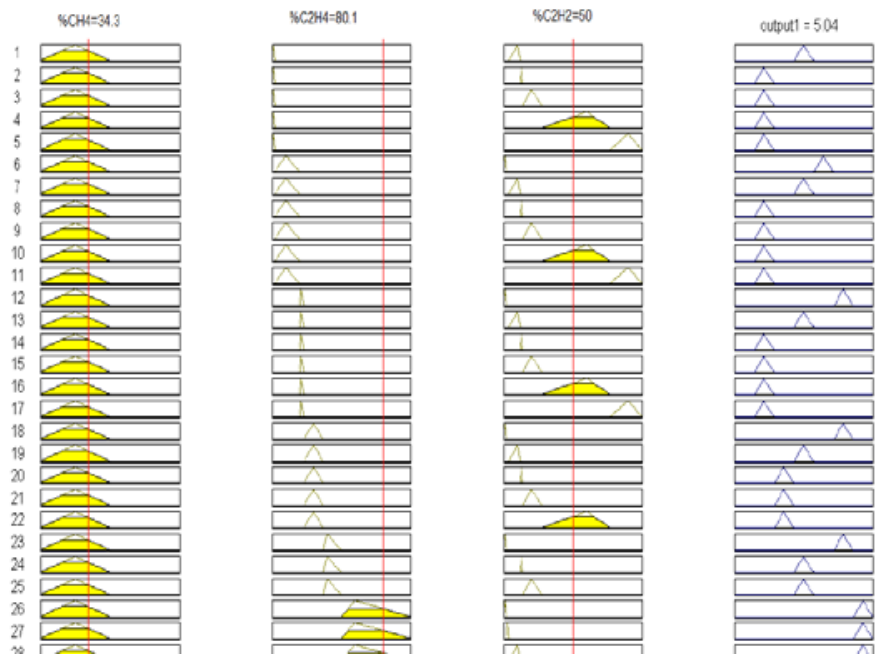

Fig. 5. Duval fuzzy rules

\section{E. Roger's Ratio Method}

The developed set of fuzzy rules relates the input and the output variables for this method is shown in Fig. 7. The model is tested with inputs, $\mathrm{C}_{2} \mathrm{H}_{2} / \mathrm{C}_{2} \mathrm{H}_{4}$ (2.5), $\mathrm{CH}_{4} / \mathrm{H}_{2}$ (2.5), $\mathrm{C}_{2} \mathrm{H}_{4} / \mathrm{C}_{2} \mathrm{H}_{6}$ (2.5) and $\mathrm{C}_{2} \mathrm{H}_{4} / \mathrm{C}_{2} \mathrm{H}_{6}$ (2.5) as detected in one of transformer oil samples DGA results. The fuzzy logic model results in 11 as shown in Fig. 7. This output is corresponding to F6 in Fig. 2, which is out of code case which reveals that
DGA results of this oil sample cannot be diagnosed using Roger's ratio method.
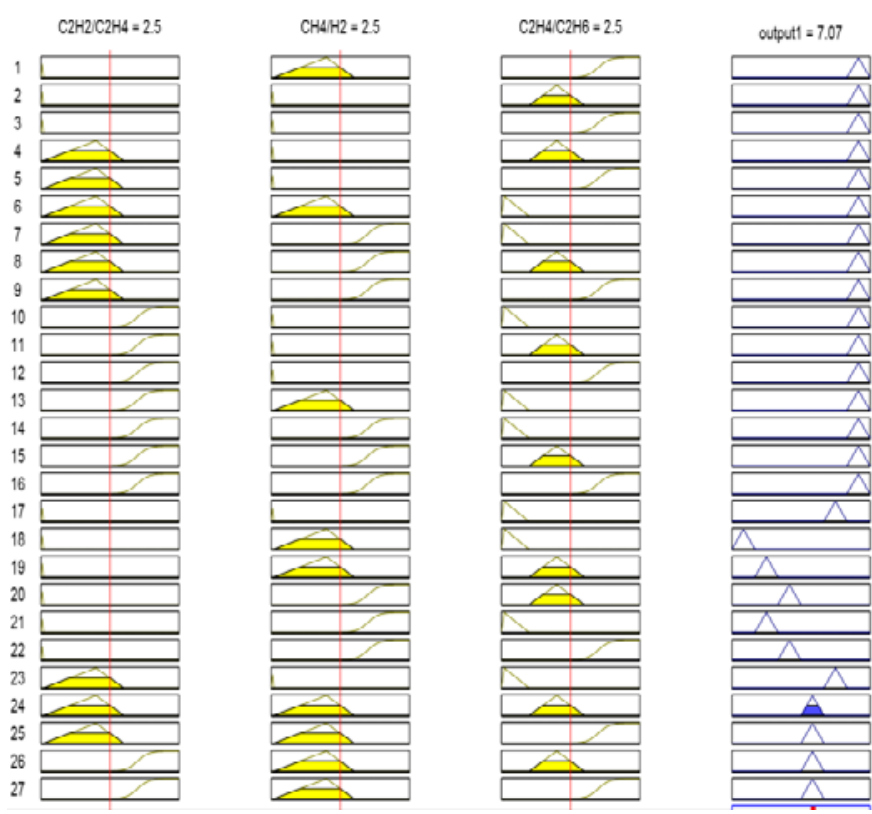

Fig. 6. IEC fuzzy rules
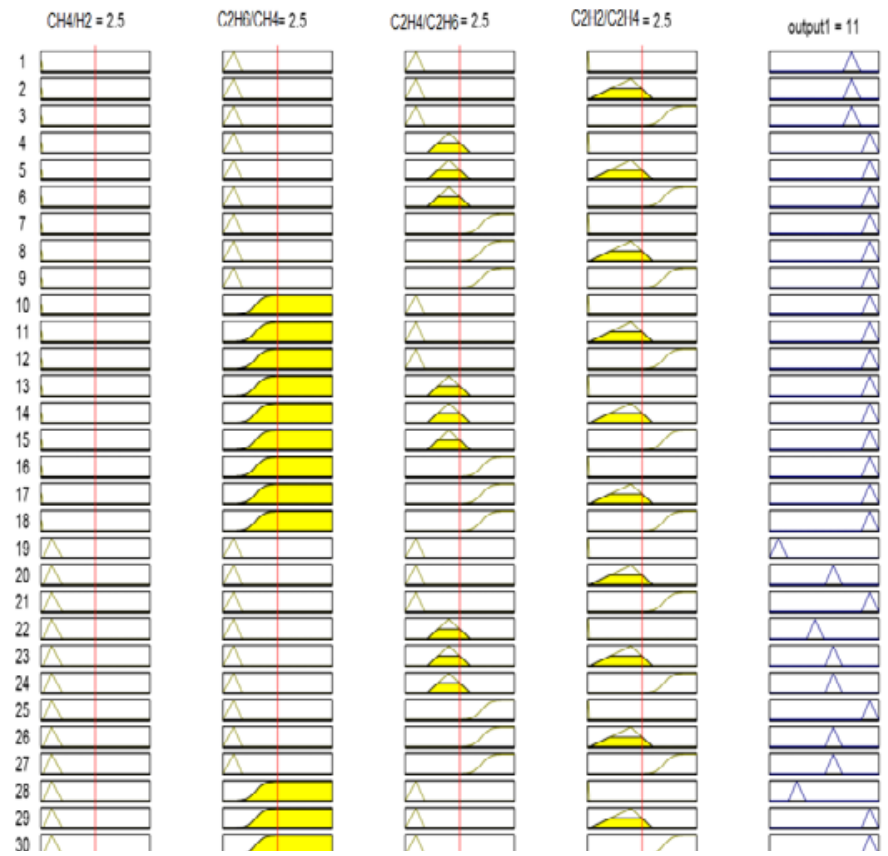

Fig. 7. Roger ratio fuzzy rules

\section{DGA AND MODEL RESULTS}

Several oil samples have been collected from different transformers of various service spans and DGA has been performed on all samples. Table II shows the DGA (in ppm) for 20 oil samples and the corresponding interpretation using traditional techniques and the developed fuzzy logic model for each method. The following oservations can be concluded from Table II. 
TABLE II

DGA RESULTS AND FUZZY LOGIC MODEL OUTPUT

\begin{tabular}{|c|c|c|c|c|c|c|c|c|c|c|c|c|c|c|c|}
\hline Sample\# & $\mathrm{H2}$ & $\mathrm{CH} 4$ & $\mathrm{C2H6}$ & $\mathrm{C} 2 \mathrm{H} 4$ & $\mathrm{C2H} 2$ & Duval & Duval & Key Gas & \begin{tabular}{|l|} 
Key Gas \\
\end{tabular} & IEC & IEC & Roger & Roger & Doern. & Doernen. \\
\hline & & & & & & Trad. & Fuzzy & Trad. & Fuzzy & Trad. & Fuzzy & Trad. & Fuzzy & Trad. & Fuzzy \\
\hline 1 & 200 & 205.9 & 250 & 740 & 1 & T3 & $\mathrm{F} 2$ & $\mathrm{~F} 2$ & $\mathrm{~F} 2$ & $\mathrm{~F} 1$ & F3 & OUT & F6 & $\mathrm{F} 1, \mathrm{~F} 2$ & $\mathrm{~F} 1$ \\
\hline 2 & 300 & 112.25 & 180 & 360 & 95 & DT & $\mathrm{F} 4$ & $\mathrm{~F} 4, \mathrm{~F} 2$ & $\mathrm{~F} 2$ & F3 & $\mathrm{F3}$ & OUT & F6 & F3 & F3 \\
\hline 3 & 56 & 334.1 & 75 & 32 & 31 & DT & $\mathrm{F} 4$ & F1 & F1 & OUT & F6 & OUT & F6 & F1,F2 & F1 \\
\hline 4 & 33 & 7.882 & 6 & 5.3 & 0.2 & T2 & $\mathrm{F} 2$ & F5 & F5 & F5 & F5 & F5 & F5 & F5 & F5 \\
\hline 5 & 176 & 652.9 & 47.7 & 75.7 & 68.7 & DT & F4 & $\mathrm{F} 1, \mathrm{~F} 2, \mathrm{~F} 4$ & F2 & OUT & F6 & OUT & F6 & $\mathrm{F} 1, \mathrm{~F} 2$ & F1 \\
\hline 6 & 70.4 & 198.9 & 28.9 & 241.2 & 10.4 & T3 & $\mathrm{F} 2$ & $\mathrm{~F} 2, \mathrm{~F} 1$ & $\mathrm{~F} 2$ & OUT & F6 & $\mathrm{F} 2$ & $\mathrm{~F} 2$ & $\mathrm{~F} 1, \mathrm{~F} 2$ & F1 \\
\hline 7 & 162 & 21.92 & 5.6 & 30 & 44 & D2 & F3 & F3,F4 & F2 & F3 & F3 & F3 & F3 & F3 & F3 \\
\hline 8 & 345 & 37.6 & 27.5 & 51.5 & 58.75 & $\mathrm{D} 2$ & F3 & $\mathrm{F} 3, \mathrm{~F} 4$ & $\mathrm{F3}$ & F3 & $\mathrm{F3}$ & F3 & $\mathrm{F3}$ & F3 & $\mathrm{F3}$ \\
\hline 9 & 181 & 0.574 & 210 & 528 & 0 & T3 & $\mathrm{F} 2$ & $\mathrm{~F} 2$ & $\mathrm{~F} 2$ & OUT & F6 & OUT & F6 & $\mathrm{F} 4$ & $\mathrm{~F} 4$ \\
\hline 10 & 172.9 & 205.9 & 172.9 & 812.5 & 37.7 & T3 & $\mathrm{F} 2$ & $\mathrm{~F} 2$ & $\mathrm{~F} 2$ & OUT & F6 & $\mathrm{F} 2$ & $\mathrm{~F} 2$ & $\mathrm{~F} 1, \mathrm{~F} 2$ & F1 \\
\hline 11 & 2587.2 & 112.25 & 4.704 & 1.4 & 0 & $\mathrm{PD}$ & F4 & $\mathrm{F} 4$ & F4 & $\mathrm{F} 4$ & $\mathrm{~F} 4$ & F4 & $\mathrm{F} 4$ & $\mathrm{~F} 4$ & F4 \\
\hline 12 & 1678 & 334.1 & 80.7 & 1005.9 & 419.1 & DT & F4 & F4 & F4 & F3 & F3 & F3 & F3 & F3 & F3 \\
\hline 13 & 206 & 7.882 & 74 & 612.7 & 15.1 & T3 & $\mathrm{F} 2$ & $\mathrm{~F} 2$ & $\mathrm{~F} 2$ & OUT & F6 & OUT & F6 & F4 & F4 \\
\hline 14 & 180 & 652.9 & 75 & 50 & 4 & T1 & F1 & F1 & F1 & F1 & F1 & F1 & F1 & $\mathrm{F} 1, \mathrm{~F} 2$ & F1 \\
\hline 15 & 34.45 & 198.9 & 3.19 & 44.96 & 19.62 & DT & $\mathrm{F} 4$ & $\mathrm{~F} 1$ & $\mathrm{~F} 1$ & OUT & F6 & OUT & F6 & $\mathrm{F} 1, \mathrm{~F} 2$ & $\mathrm{~F} 1$ \\
\hline 16 & 51.2 & 21.92 & 5.1 & 52.8 & 51.6 & D2 & F3 & $\mathrm{F3}$ & $\mathrm{F} 3$ & $\mathrm{F3}$ & $\mathrm{F3}$ & $\mathrm{F} 3$ & $\mathrm{F3}$ & F3 & $\mathrm{F} 3$ \\
\hline 17 & 106 & 37.6 & 4 & 28 & 37 & D2 & F3 & $\mathrm{F} 3, \mathrm{~F} 4$ & F3 & $\mathrm{F3}$ & F3 & F3 & $\mathrm{F} 3$ & $\mathrm{F3}$ & F3 \\
\hline 18 & 180.85 & 0.574 & 0.234 & 0.188 & 0 & $\mathrm{~T} 2$ & $\mathrm{~F} 2$ & $\mathrm{~F} 4$ & $\mathrm{~F} 4$ & $\mathrm{~F} 4$ & $\mathrm{~F} 4$ & $\mathrm{~F} 4$ & $\mathrm{~F} 4$ & $\mathrm{~F} 4$ & $\mathrm{~F} 4$ \\
\hline 19 & 27 & 205.9 & 42 & 63 & 0.2 & $\mathrm{~T} 2$ & $\mathrm{~F} 2$ & $\mathrm{~F} 1, \mathrm{~F} 2$ & F2 & F2 & $\mathrm{F} 2$ & OUT & F6 & $\mathrm{F} 1, \mathrm{~F} 2$ & F1 \\
\hline 20 & 138.8 & 112.25 & 6.77 & 62.8 & 9.55 & DT & F4 & $\mathrm{F} 4, \mathrm{~F} 2$ & $\mathrm{~F} 2$ & F3 & F3 & F3 & F3 & F3 & $\mathrm{F} 3$ \\
\hline
\end{tabular}

Ratio methods such as Roger and IEC methods may lead to out of code output (e.g. samples \# 1, 3, 9, 15) and the oil sample can not be interpreted using these techniques in this case.

All existing DGA interpretation techniques do not necessarily lead to the same conclusion for the same oil sample (e.g. samples \# 5, 6, 20).

The developed fuzzy logic model for each technique is effectively conclude the same result of the traditional interpretation approach as can be shown in all the 20 samples in table II.

In some cases, traditional interpretation approach may lead to more than one result (e.g. key gas in sample \# 5). To avoid this in the developed fuzzy logic model, triangular membership functions without any overlapping as shown in Fig. 2 were selected for the output of the model.

It is worth to mention that the output of Duval traditional method is based on Duval triangular shown in Fig. 8. To maintain consistency among all fuzzy logic models, zones within Duval triangle are integrated into the fault conditions shown in Table I.

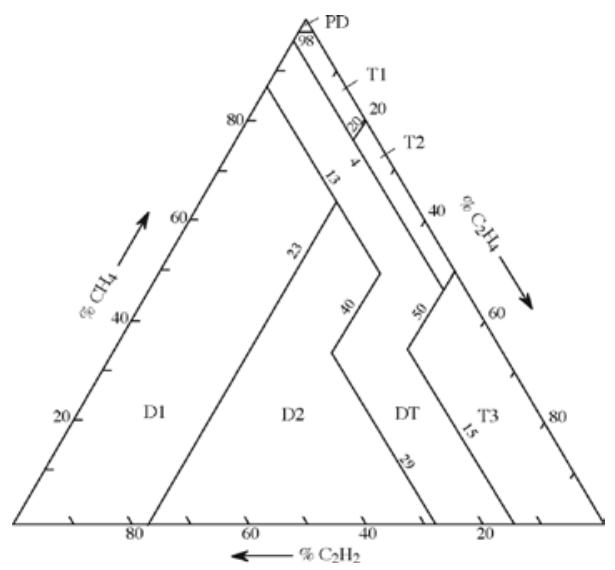

Fig. 2. Duval's Triangle [15].

\section{CONCLUSION}

This paper introduces a fuzzy logic model for various DGA interpretation techniques such as Doernenburg, IEC, Rogers ratio and Duval triangle methods. The fuzzy logic models are developed based on 2000 DGA results that have been collected from various in-service and faulty transformers. Results show that all interpretation techniques for DGA results do not necessarily lead to the same conclusion and they may result in inconsistent outcomes for the same oil sample. Results also show the accuracy of the developed fuzzy logic models in DGA interpretation and classification. These models are easy to implement and they do not call for an expert to interpret the DGA results. These models can be used to standardize the interpretation of DGA results.

\section{REFERENCES}

[1] T. K. Saha, "Review of modern diagnostic techniques for assessing insulation condition in aged transformers," Dielectrics and Electrical Insulation, IEEE Transactions on, vol. 10, pp. 903-917, 2003.

[2] M. Arshad, "Remnant Life Estimation Model Using Fuzzy Logic for Power Transformer Asset Management," PhD thesis, Curtin University, 2005.

[3] X. Liu, F. Zhou, and F. Huang, "Research on on-line DGA using FTIR [power transformer insulation testing]," 2002, pp. 1875-1880 vol.3.

[4] "IEEE guide for the interpretation of gases generated in oil-immersed transformers," IEEE Std C57.104-2008.

[5] V. G. Arakelian, "Effective diagnostics for oil-filled equipment," Electrical Insulation Magazine, IEEE, vol. 18, pp. 26-38, 2002.

[6] R. R. Rogers, "IEEE and IEC Codes to Interpret Incipient Faults in Transformers, Using Gas in Oil Analysis," Electrical Insulation, IEEE Transactions on, vol. EI-13, pp. 349-354, 1978.

[7] M. Duval, "New techniques for dissolved gas-in-oil analysis," Electrical Insulation Magazine, IEEE, vol. 19, pp. 6-15, 2003.

[8] N. A. Muhamad, B. T. Phung, and T. R. Blackburn, "Comparative study and analysis of DGA methods for mineral oil using fuzzy logic," in Power Engineering Conference, 2007. IPEC 2007. International, 2007.

[9] M. Hongzhong, L. Zheng, P. Ju, H. Jingdong, and Z. Limin, "Diagnosis of power transformer faults on fuzzy three-ratio method," in Power Engineering Conference, 2005. IPEC 2005. The 7th International, 2005.

[10] W. Zhen, L. Yilu, and P. J. Griffin, "Neural net. and expert system diagnose transformer faults," Computer Applications in Power, IEEE, vol. 13, pp. 5055, 2000.

[11] S. Mofizul Islam, T. Wu, and G. Ledwich, "A novel fuzzy logic approach to transformer fault diagnosis," Dielectrics and Electrical Insulation, IEEE Transactions on, vol. 7, pp. 177-186, 2000.

[12] A. Singh and P. Verma, "A review of intelligent diagnostic methods for condition assessment of insulation system in power transformers," in Condition Monitoring and Diagnosis, 2008. CMD 2008. International Conference on, 2008, pp. 1354-1357.

[13] M. Wang, A. J. Vandermaar, and K. D. Srivastava, "Review of condition assessment of power transformers in service," Electrical Insulation Magazine, IEEE, vol. 18, pp. 12-25, 2002.

[14] H. Li and M. Gupta, "Fuzzy Logic and Intelligent Systems," in International Series in Intelligent Technologies: Kluwer Academic Publisher 1995.

[15] M. Duval, "The duval triangle for load tap changers, non-mineral oils and low temperature faults in transformers", IEEE Electr. Insul. Mag., Vol. 24, No. 6, pp. 22-29, 2008. 